\title{
Microsatellite characterization of Plasmodium falciparum from symptomatic and non-symptomatic infections from the Western Amazon reveals the existence of non-symptomatic infection-associated genotypes
}

\author{
Rosimeire Cristina dalla Martha, Mauro Sughiro Tada, \\ Ricardo Godoi de Mattos Ferreira*, Luiz Hildebrando Pereira da Silva, \\ Gerhard Wunderlich ${ }^{* /+}$
}

Centro de Pesquisa em Medicina Tropical, Porto Velho, RO, Brasil *Departamento de Parasitologia, Instituto de Ciências Biomédicas, Universidade de São Paulo, Av. Prof. Lineu Prestes 1374, 05508-900 São Paulo, SP, Brasil

In Western Amazon areas with perennial malaria transmission, long term residents frequently develop partial immunity to malarial infection caused either by Plasmodium falciparum or P. vivax, resulting in a considerable number of non-symptomatically infected individuals. For yet unknown reasons, these individuals sporadically develop symptomatic malaria. In order to identify if determined parasite genotypes, defined by a combination of eleven microsatellite markers, were associated to different outcomes - symptomatic or asymptomatic malaria - we analyzed infecting P. falciparum parasites in a suburban riverine population. Despite of detecting a high degree of diversity in the analyzed samples, several microsatellite marker alleles appeared accumulated in parasites from non-symptomatic infections. This result may be interpreted that a number of microsatellites, which are not directly related to antigenic features, could be associated to the outcome of malarial infection. The result may also point to a low frequency of recombinatorial events which otherwise would dissociate genes under strong immune pressure from the relatively neutral microsatellite loci.

Key words: non-symptomatic malaria - Plasmodium falciparum - microsatellites - genotyping

Malaria is one of the main infectious diseases of the world, more specifically in developing or underdeveloped tropical regions of the planet. Worldwide, 2-3 million individuals, mostly children under 5 years, succumb to Plasmodium falciparum caused disease. More than 2 billion people are at risk to acquire malarial infection and 500 million or more cases are estimated to occur annually (Snow et al. 2005). In the Western Amazon, acute malarial infection with deaths are encountered mainly in gold digger or wood logging camps with a high influx of malaria-naïve individuals (Sawyer 1988), whereas stable settlements along rivers rarely report fatal cases but show a high prevalence of non-symptomatic infections (Alves et al. 2002) which function as a silent source of transmission (Alves et al. 2005). Recently, during a major malaria control effort in the Candelária suburb of Porto Velho, capital of Rondônia, many non-symptomatic individuals infected with either $P$. falciparum or $P$. vivax were detected. Interestingly, between the crosssectional surveys involving most of the citizens in the area, symptomatic malaria attacks were also reported in

Financial support: Fapesp

RGMF and GW are supported by CNPq fellowships.

+ Corresponding author: gwunder@usp.br

Received 17 October 2006

Accepted 18 April 2007 the same population. We wondered if different parasite populations could be responsible for the different outcome of malaria infections in this area. In a previous report from parasite samples from French-Guyana (Ariey et al. 2001), different genotypes of $P$. falciparum and certain alleles of polymorphic genes were associated to severe disease. In another study in Vietnam (Ferreira et al. 2002), where the circulating $P$. falciparum were genotyped using neutral microsatellites, the clinical outcome of the individual malaria cases could not be associated to specific $P$. falciparum genotypes.

In the Western Amazon, circulating P. falciparum genotypes seem to share a high number of variant antigens suggesting a low frequency of truly recombinatory events and favoring inbreeding of circulating strains (Albrecht et al. 2006). Taking into account the relatively low transmission (Gil et al. 2003) in the study area, we asked if distinct $P$. falciparum strains could be identified in the observed symptomatic or non-symptomatic infections in the same population. For this, multilocus microsatellite genotyping was conducted on the circulating strains of 43 cases of uncomplicated symptomatic and non-symptomatic P. falciparum infections, occurring during a 1 year-interval in a population exposed to the same risk of infecting mosquito bites.

\section{MATERIALS AND METHODS}

Study area, patients and origin of parasite samples - The study area Vila Candelária $\left(8^{\circ} 47^{\prime} 08^{\prime \prime} \mathrm{S}, 63^{\circ} 55^{\prime}\right.$ $04 " \mathrm{~W}$ ) is situated at $2 \mathrm{~km}$ of the centre of Porto Velho, capital of the state of Rondônia, Brazil. The climate is 
tropical humid with a rainy season from October to April (around 2,500 $\mathrm{mm}$ rain precipitation) and a relatively dry season from May to September (500 $\mathrm{mm}$ or less of rain precipitation). The temperature ranges from $18^{\circ}$ to $38^{\circ} \mathrm{C}$ and the humidity, with exception of short periods in the dry season, is always higher than $80 \%$. Vila Candelária extends from the right Madeira bank to more elevated areas, around $400 \mathrm{~m}$ distant from the riverbank. The population of Candelária ( $\sim 300$ individuals) is relatively stable and of mixed indigenous, negro and Caucasian origin. Bate Estaca is located immediately upstream of Candelária and has similar populational characteristics, but only 80-90 inhabitants. The herein employed blood samples were collected during two cross-sectional surveys and continuous surveillance of the population during April and September 2001 in Candelária from people between 3 and 49 years of age and several years of residence in malaria-endemic areas. Individuals presenting symptomatic infections between the cross-sectional surveys in Candelária or Bate Estaca actively sought treatment in the Candelária health post. In total, 24 samples from asymptomatic infections and 10 samples from symptomatic samples were collected in the Candelária area. Another part of the blood samples from symptomatic patients $(\mathrm{n}=9)$ was collected in the Malaria and Dengue Outpatient Clinic of the Centre of Tropical Medicine in Porto Velho. These patients acquired their infections at different locations throughout the Porto Velhocounty in a diameter of approx. $80 \mathrm{~km}$. All participating patients gave their written consent before contributing blood samples. Participants were considered non-symptomatic if they (i) did not report any febrile episodes two weeks before blood retrieval, (ii) did not present any symptoms on the day of blood retrieval and throughout the following 60 days. Parasitemias in these samples were sub-microscopical (approx. 1-100 IRBC per $\mu \mathrm{l}$ erythrocytes). Non-symptomatic individuals were not treated for malaria since they chose to do so.

Symptomatic, non-severe participants with parasitemias between 0.1 and $2 \%$ presenting typical malaria symptoms such as fever, myalgia, nausea, sweating, and headache were immediately treated after malaria diagnosis and blood retrieval. Ethical clearance was obtained beforehand from the Federal Ethics commission.

Preparation of parasite genomic DNA - Five $\mathrm{ml}$ of blood were collected in heparinized vacutainer tubes and centrifuged for $6 \mathrm{~min}$ at $2000 \mathrm{~g}$ at room temperature (RT). Fractions of plasma, buffy coat and infected red blood cells (IRBC) were separated and frozen at $-20^{\circ} \mathrm{C}$ until use. Genomic DNA of parasites was purified following the previously published protocol (Schlichtherle et al. 2000) and frozen at $-20^{\circ} \mathrm{C}$ until use.

Parasite genotyping and microsatellite PCR - Initially, each genomic DNA was tested for the presence or not of $P$. falciparum genomic DNA (gDNA). For this purpose, the oligonucleotides and PCR conditions introduced by Snounou (1996) were applied. Briefly, each gDNA was amplified with primers specific for the ribosomal RNA genes and afterwards with a second set of primers, detecting either P. falciparum P. vivax, or P. malariae.
For the evaluation of the circulating $P$. falciparum haplotypes, defined by a combination of marker sizes of eleven microsatellite loci, gDNAs were amplified in the nested PCR protocol published by Anderson et al. (1999) using the oligonucleotide primers used therein. In the second PCR reaction, one Cy5-labeled primer was used to permit semi-automatic analysis of the marker sizes in an ALF2 (Amersham Pharmacia) automated sequencer. For the size analysis of fragments, a molecular weight marker containing an internal standard of $60 \mathrm{bp}$ added to every sample, and length markers of $60 \mathrm{bp}, 97 \mathrm{bp}, 175 \mathrm{bp}$, and $219 \mathrm{bp}$ were used.

Data analysis - Fragments detected by the ALF2 sequencer were size-determined using the AlleleLinks 1.0 software (Amersham Pharmacia). When multiple peaks were detected per microsatellite marker and the additionally observed peak was at least 33\% the size of the largest peak, the infecting parasite population was classified as polyclonal. For further analysis, only the main peaks were considered. The microsatellite markers of different gDNAs samples were analyzed using the Arlequin 2000 software (Schneider et al. 2000). The molecular diversity index for each sample was calculated and the population differentiation was expressed as Reynolds' distance $\left(\mathrm{R}_{\mathrm{ST}}\right)$ for the three groups of parasite DNAs as listed in Table I.

Significance of association tests with single microsatellite markers testing for uneven distribution in gDNAs stemming from symptomatic versus asymptomatic infections including or not the outside-Candelária sample SCP were performed using Pearson's Chi-square tests (Yates corrected) in SPSS (version 11). Associations were considered significant when $p$ values were below 0.05 .

\section{TABLE I}

Genetic distance of genotypes from different samples. The genetic distances $\left(\mathrm{R}_{\mathrm{ST}}\right.$ values) between all samples were calculated with Arlequin

\begin{tabular}{lcc}
\hline & AVC & SVC/SBE \\
\hline AVC & 0 & \\
SVC/SBE & $0,41(p<0,001)$ & 0 \\
SCP & $0,16(p=0,036)$ & $0,17(p=0,009)$ \\
SCP+SVC/SBE & $0,24(p<0,001)$ & \\
\hline
\end{tabular}

\section{RESULTS}

Forty-three field DNA samples were analyzed and all infections were solely caused by P. falciparum and no mixed infection with $P$. vivax were detected by speciesspecific PCR (data not shown). A total of 28 showed more than one haplotype, identified by two alleles for at least one microsatellite marker. From the 43 dominant haplotypes, 37 were different (Table III).

In the following, the genetic heterogeneity of the different samples was computed on the basis of micro-satellite data. All parasite samples showed a high molecu- 
TABLE II

Significant associations of microsatellite markers from parasites causing symptomatic (S) or non-symptomatic (NS) infections

\begin{tabular}{lccccccr}
\hline $\begin{array}{l}\text { A - Comparison of all genotypes, classified for "symptomatic/ } \\
\text { non-symptomatic" }\end{array}$ & & & & & \\
TA1 & & & & & & & Total \\
Allele size & 171 & 174 & 177 & 180 & 183 & & \\
S & 4 & 4 & 1 & & 10 & & 19 \\
NS & & 11 & 10 & 1 & 2 & & 24 \\
Sum & 4 & 16 & 11 & & 11 & & 43 \\
POLY- $\alpha$ & & & & & & & Total \\
Allele size & 152 & 155 & 164 & 182 & 185 & 191 & \\
S & 2 & & 2 & 9 & 4 & 1 & $18^{*}$ \\
NS & 13 & 2 & 1 & 8 & & & 24 \\
Sum & 15 & 2 & 3 & 17 & 4 & 1 & 42 \\
TAA60 & & & & & & & Total \\
Allele size & 75 & 78 & 84 & 87 & 93 & & \\
S & 13 & 3 & 1 & 1 & 1 & & 19 \\
NS & 8 & 16 & & & & & 24 \\
Sum & 21 & 19 & 1 & 1 & 1 & & 43 \\
TAA42 & & & & & & & Total \\
Allele size & 188 & 191 & 194 & 197 & 200 & 203 & \\
S & 4 & 1 & 1 & & 3 & 10 & 19 \\
NS & 10 & & & 10 & & 4 & 24 \\
Sum & 14 & 1 & 1 & 10 & 3 & 14 & 43 \\
& & & & & &
\end{tabular}

B - Comparison of genotypes from the Candelária area, classified for "symptomatic/non-symptomatic"

TA1

\begin{tabular}{|c|c|c|c|c|c|c|c|}
\hline Allele size & 174 & 177 & 180 & 183 & & & \\
\hline S & 3 & 1 & & 6 & & & 10 \\
\hline NS & 11 & 10 & 1 & 2 & & & 24 \\
\hline Sum & 14 & 11 & 1 & 8 & & & 34 \\
\hline \multicolumn{7}{|l|}{ POLY- $\alpha$} & Total \\
\hline Allele size & 152 & 155 & 164 & 182 & 185 & & \\
\hline S & & & 1 & 5 & 3 & & 9 \\
\hline NS & 13 & 2 & 1 & 8 & & & 24 \\
\hline sum & 13 & 2 & 2 & 13 & 3 & & 33 \\
\hline \multicolumn{7}{|l|}{ TAA42 } & otal \\
\hline Allele size & 188 & 191 & 194 & 197 & 200 & 203 & \\
\hline S & 2 & 1 & 1 & & 1 & 5 & 10 \\
\hline NS & 10 & & & 10 & & 4 & 24 \\
\hline sum & 12 & 1 & 1 & 10 & 1 & 9 & 34 \\
\hline
\end{tabular}

A: all genotypes and locations were tested. B: results from genotypes of parasites stemming exclusively from the Candelária area (including Bate Estaca). The significance $(\mathrm{p}<0.05)$ of allele distribution differences was calculated using Pearson's chi square test. * means that of one gDNA sample the indicated microsatellite marker could not be amplified.

lar diversity index (MDI), with the highest value found in parasites from different origins outside the Candelária area. The symptomatic infection-associated genotypes SVC/SBE were less divergent than the both other samples (SVC/SBE group, MDI: $0.43 \pm 0.27$ versus AVC group MDI: $0.49 \pm 0.27$ and SCP group, MDI: $0.53 \pm$ 0.32 ). One genotype was found in all groups (corresponding to AVC4, Table III).

When the different parasite genotypes were compared between the three groups considering the genetic distance expressed as $\mathrm{R}_{\mathrm{ST}}$ values, a significant differentiation of genotype samples was observed and all samples were different from each other. Genotypes from the asymptomatic sample AVC showed the most significant difference to the sample from symptomatic infections of the same area (SVC/SBE, Table I). When the genotypes were classified in parasite genotypes from symptomatic or non-symptomatic infections, a significant difference between the two groups could be observed (Table I).

Given the apparent population differentiation, we asked which microsatellite loci were associated with symptomatic or non-symptomatic forms of infection. After analysis of the frequencies of allele distribution per microsatellite marker, comparing the group of $P$. falciparum parasites isolated from symptomatic (SVC/ $\mathrm{SBE} / \mathrm{SCP}$ ) with non-symptomatic infections (AVC), in 4 of 11 loci significantly different allele distributions were detected. When only parasite genotypes from the Candelária district were considered, still 3 of 11 markers showed significant differences in their allele distribution upon comparison of symptomatic versus nonsymptomatic associated genotypes (Table II). Notably, of the locus Ta1, the 174bp and 177bp alleles, in the locus Taa42 the alleles 188bp and 197bp and the allele of $152 \mathrm{bp}$ of the Polya locus were associated with nonsymptomatic parasite genotypes considering or not the SCP sample. When the SCP sample was considered, the loci TAA60 showed also strong and significant accumulation of the $78 \mathrm{bp}$ allele in the asymptomatic sample.

\section{DISCUSSION}

In the rural areas of the Western Amazon, cases of non-symptomatic malarial infections caused either by $P$. falciparum or by $P$. vivax (Alves et al. 2002) are frequently encountered and individuals of these areas usually have generally strong responses against malarial antigens (Ferreira et al. 1994). Among these populations, symptomatic infections are also observed. In order to find parameters which are responsible for the malarial infections in an otherwise semi-immune population, the genotypes of the infecting $P$. falciparum parasites were analyzed by multilocus microsatellite typing.

We first looked at the polyclonality of infections. According to previous results from Druilhe and colleagues (Druilhe et al. 1998), a high overall proportion of mixed genotypes per infection was identified, which does not necessarily mean the occurrence of profoundly different parasites in terms of major antigens (Hoffmann et al. 2006). The observed frequency of mixed infections was significantly lower in the groups SCP and SVC (symptomatic infections) when compared to AVC (asymptomatic), however, we believe that this result does not exclude that indeed more than one parasite genotype is circulating in the actual infections. We rather believe that the applied method may be prone to underestimate the presence of additional genotypes when one is clearly dominant, as is frequently the case in natural symptomatic infections (Jafari et al. 2004).

Two of the three parasite samples were from a rather limited area spanning no more than $4 \mathrm{~km}$ in length and $500 \mathrm{~m}$ wide along the Madeira River. We expected in 
TABLE III

Microsatellite markers from the isolates. AVC isolates from non-symptomatic Plasmodium falciparum infections were identified in two cross-sections, and all other isolates were from symptomatic infections from the same area (SBE and SVC) or from the medical attendance post (SCP)

\begin{tabular}{|c|c|c|c|c|c|c|c|c|c|c|c|}
\hline \multicolumn{12}{|c|}{ Microsatellite marker $\rightarrow$} \\
\hline Isolate & TA1 & Polya & TAA60 & ARA2 & Pfg377 & PfPK 2 & TAA87 & TAA109 & TAA81 & TAA42 & 2490 \\
\hline AVC1 & $174 / 180$ & 155 & 78 & 66 & 96 & $162 / 171$ & $96 / 114$ & 166 & 121 & 197 & 93 \\
\hline AVC2 & $174 / 183$ & 182 & 78 & 66 & 96 & 171 & 114 & 166 & 121 & $203 / 188$ & 87 \\
\hline AVC3 & 177 & 155 & 75 & 66 & 96 & 177 & 114 & 163 & 124 & 188 & 84 \\
\hline $\mathrm{AVC}^{\#}{ }^{\#}$ & 183 & 182 & 75 & 66 & 96 & 171 & 114 & 166 & 121 & 203 & 87 \\
\hline AVC5 & $174 / 180$ & 182 & 78 & 66 & 96 & 171 & 99 & 166 & 121 & 188 & 93 \\
\hline AVC6 & 174 & 182 & $75 / 78$ & 66 & 96 & 177 & $111 / 114$ & 166 & 121 & 197 & 93 \\
\hline AVC7 & 174 & 182 & 78 & 66 & 99 & $162 / 171$ & 114 & 166 & $115 / 121$ & 197 & 93 \\
\hline AVC8 & 174 & 164 & 78 & 66 & 96 & $171 / 177$ & 114 & 166 & $121 / 124$ & 197 & 93 \\
\hline AVC9 & 174 & 152 & 78 & 66 & 96 & 177 & 114 & 166 & $121 / 127$ & 197 & 87 \\
\hline AVC10 & $177 / 183$ & 182 & 78 & 66 & 96 & 177 & $99 / 114$ & 163 & $121 / 139$ & 203 & 87 \\
\hline AVC11 & 174 & 152 & 75 & 66 & $96 / 99$ & $171 / 177$ & 114 & 163 & 121 & 197 & 87 \\
\hline AVC12 & 177 & 152 & 75 & 66 & 96 & 177 & 99 & 166 & 121 & 188 & 93 \\
\hline AVC13 & 177 & $149 / 152$ & 75 & 66 & 96 & 177 & 99 & 166 & 121 & 188 & 84 \\
\hline AVC14 & 174 & 182 & $78 / 84$ & 66 & 99 & 177 & 111 & 163 & 118 & 188 & 90 \\
\hline $\mathrm{AVC} 15^{\#}$ & 183 & 182 & $75 / 78$ & 66 & 96 & 171 & 114 & 166 & 121 & 203 & 87 \\
\hline AVC16 $\$$ & 177 & 152 & 78 & 66 & 96 & 177 & 99 & 166 & 121 & 188 & 84 \\
\hline AVC17 & 177 & 152 & 78 & 66 & 96 & $171 / 177$ & 99 & 166 & 121 & $188 / 197$ & 84 \\
\hline AVC18 & 177 & 152 & $75 / 78$ & 66 & 96 & 177 & 99 & 175 & 121 & 188 & 84 \\
\hline AVC19\$ & 177 & 152 & 78 & 66 & 96 & 177 & 99 & 166 & 121 & 188 & 84 \\
\hline AVC20 & 177 & 152 & 78 & 66 & $96 / 99$ & $171 / 177$ & 114 & 175 & 121 & $203 / 197$ & 93 \\
\hline AVC21 & 174 & 152 & 78 & 66 & 96 & 171 & 114 & 166 & 121 & $197 / 203$ & 93 \\
\hline $\mathrm{AVC} 22^{\$}$ & 177 & 152 & 78 & 66 & 96 & $171 / 177$ & 99 & 166 & 121 & $188 / 197$ & 84 \\
\hline AVC23 & 174 & 152 & 78 & 66 & 96 & $171 / 177$ & 114 & 175 & 121 & $197 / 203$ & 93 \\
\hline AVC24 & 174 & $152 / 170$ & 78 & 66 & 96 & 171 & $93 / 114$ & 178 & $121 / 124$ & 197 & 93 \\
\hline $\mathrm{H}_{\mathrm{obs}}$ & 0,59 & 0,66 & 0,43 & 0,00 & 0,16 & 0,60 & 0,67 & 0,53 & 0,24 & 0,65 & 0,71 \\
\hline $\mathrm{H}_{\mathrm{exp}}^{\mathrm{oss}}$ & 0,70 & 0,83 & 0,52 & 0,00 & 0,52 & 0,70 & 0,83 & 0,78 & 0,78 & 0,70 & 0,78 \\
\hline SVC1 & 183 & 182 & 78 & 66 & 96 & 171 & 114 & 166 & 121 & 203 & $93 / 87$ \\
\hline $\mathrm{SVC}^{\#}$ & 183 & 182 & 75 & 66 & 96 & 171 & 114 & 166 & 121 & 203 & 87 \\
\hline SVC3 & 183 & 185 & 75 & 66 & 96 & 171 & 114 & 166 & 121 & 203 & 93 \\
\hline SVC4 & $168 / 174$ & $176 / 185$ & 78 & 66 & $96 / 99$ & 171 & 114 & $166 / 175$ & 121 & 194 & 93 \\
\hline SVC5 & $177 / 180$ & - & 93 & 66 & - & 171 & 114 & 175 & - & 200 & - \\
\hline SVC6 & 174 & 182 & 84 & 66 & 99 & 177 & 111 & 175 & 118 & 191 & 90 \\
\hline SBE1 & $174 / 183$ & 182 & $75 / 78$ & 66 & $96 / 99$ & $171 / 177$ & 114 & 166 & 124 & 203 & 87 \\
\hline SBE2 & $174 / 177$ & 164 & 78 & 66 & 99 & 177 & 114 & 166 & 124 & 188 & 84 \\
\hline SBE3 & 183 & 185 & $75 / 84$ & 66 & 96 & $171 / 177$ & 114 & 166 & 118 & $188 / 203$ & 90 \\
\hline $\mathrm{SBE}^{\#}$ & $174 / 183$ & 182 & $75 / 78$ & 66 & 96 & 171 & 114 & 166 & 121 & $197 / 203$ & 87 \\
\hline $\mathrm{H}_{\mathrm{obs}}$ & 0,71 & 0,77 & 0,71 & 0,00 & 0,52 & 0,53 & 0,20 & 0,36 & 0,74 & 0,84 & 0,83 \\
\hline $\mathrm{H}_{\mathrm{exp}}^{\mathrm{os}}$ & 0,83 & 0,83 & 0,83 & 0,00 & 0,56 & 0,56 & 0,56 & 0,56 & 0,74 & 0,93 & 0,83 \\
\hline $\mathrm{SCP} 1$ & 183 & 191 & 75 & 66 & 96 & 171 & 99 & 166 & 124 & 203 & 87 \\
\hline SCP2 & 171 & $152 / 185$ & 75 & 66 & 96 & 177 & 99 & 166 & 124 & 203 & 84 \\
\hline SCP3 & 183 & 152 & 87 & 72 & 96 & 174 & 99 & 175 & 121 & 203 & 84 \\
\hline SCP4 & 183 & 152 & 87 & 72 & 96 & 174 & 99 & 175 & 121 & 203 & 84 \\
\hline $\mathrm{SCP}^{\#}$ & 183 & 182 & 75 & 66 & 96 & 171 & 114 & 166 & 121 & 203 & 87 \\
\hline SCP6 & 174 & 164 & 75 & 66 & 99 & 177 & 114 & 166 & 124 & 188 & 84 \\
\hline SCP7 & 171 & 182 & 75 & 66 & 99 & 177 & 99 & 166 & 124 & 200 & 84 \\
\hline SCP8 & 171 & 152 & 75 & 66 & 99 & 174 & 99 & 163 & 121 & 188 & 84 \\
\hline SCP9 & 171 & 182 & 75 & 66 & 99 & $168 / 177$ & 114 & 166 & $118 / 121$ & 203 & $84 / 87$ \\
\hline $\mathrm{H}_{\mathrm{obs}}$ & 0,67 & 0,75 & 0,22 & 0,22 & 0,56 & 0,72 & 0,50 & 0,56 & 0,56 & 0,67 & 0,39 \\
\hline $\mathrm{H}_{\mathrm{exp}}^{\mathrm{obs}}$ & 0,75 & 0,84 & 0,56 & 0,56 & 0,56 & 0,75 & 0,56 & 0,75 & 0,56 & 0,75 & 0,56 \\
\hline $\mathrm{H}_{\text {obs }}^{\text {ex }}$ sym & 0,72 & 0,76 & 0,62 & 0,11 & 0,56 & 0,65 & 0,53 & 0,44 & 0,65 & 0,74 & 0,74 \\
\hline $\mathrm{H}_{\text {exp }}^{\text {sos }}$ sym & 0,84 & 0,94 & 0,90 & 0,56 & 0,56 & 0,75 & 0,75 & 0,75 & 0,75 & 0,94 & 0,84 \\
\hline $\mathrm{H}_{\mathrm{obs}}^{\mathrm{exp}}$ all & 0,74 & 0,73 & 0,57 & 0,05 & 0,38 & 0,62 & 0,60 & 0,49 & 0,46 & 0,75 & 0,73 \\
\hline $\mathrm{H}_{\text {exp }}^{\text {oxs }}$ all & 0,82 & 0,90 & 0,82 & 0,51 & 0,51 & 0,77 & 0,82 & 0,77 & 0,77 & 0,85 & 0,77 \\
\hline
\end{tabular}

"-" means that no readable signal was obtained after two repetitions. Numbers in italic indicate non-dominant additional peaks in mixed isolates. Symbols “\#” and "\$” highlight identical haplotypes encountered in different isolates. The observed heterozygosity $\left(\mathrm{H}_{\mathrm{obs}}\right)$ values for each marker (dominant values) in subgroups were calculated as follows: $H_{o b s}=n /(n-1) *\left(1-S^{k}\left(p_{i}\right)^{2}\right)$, where $n$ is the number of gDNAs per subgroup, $\mathrm{k}$ the number of different alleles and $\mathrm{p}$ the observed relative frequency of each allele. The expected heterozygosity $\left(\mathrm{H}_{\mathrm{exp}}\right)$ was $\mathrm{H}_{\mathrm{exp}}=\mathrm{n} /(\mathrm{n}-1) *\left(1-\mathrm{k}^{*}((\mathrm{n} / \mathrm{k}) / \mathrm{n})\right)$. " $\mathrm{H}_{\mathrm{exp}}$ sym", " $\mathrm{H}_{\mathrm{obs}}$ sym", " $\mathrm{H}_{\mathrm{exp}}$ all" and " $\mathrm{H}_{\mathrm{obs}}$ all" show the heterozygosity values for gDNAs from all symptomatic (SCP/SBE/SVC) and all infections, respectively. 
this population a rather limited repertoire of haplotypes similar to what was shown for other locations in the Amazon (Machado et al. 2004) which was not the case: The AVC group for example is as disperse as the SCP sample containing genotypes from infections from the entire county of Porto Velho. Upon $\mathrm{R}_{\mathrm{ST}}$ analysis, genotypes from the Outpatient Clinic-group SCP showed significant genetic differentiation from the Candelária area, which was expected due to the different geographical origin of infections. Significant differences were also detected between genotypes infecting individuals in the Candelária area developing malaria symptoms or not. To our knowledge for the first time, it could be demonstrated that determined microsatellite marker sizes were associated with non-symptomatic outcomes. Two hypotheses may explain this finding. Firstly, the locally occurring asymptomatic-associated genotypes are less virulent than their symptomatic malaria-associated counterparts, in analogy to severe Malaria-associated genotypes in French Guyana (Ariey et al. 2001). This hypothesis is rather unlikely, since two parasite genotypes were found in asymptomatic and symptomatic samples. However, one must be aware that identical haplotypes may not necessarily mean a completely shared repertoire of virulence-relevant antigens.

Another hypothesis is that the population of Candelária may be immune against parasites bearing the genotypes (and their related antigens) encountered in the AVC sample, however, they are not immune against other genotypes which may be introduced to the area by 'outsiders' due to the significant tourist movement observed in Candelária, possibly explaining why mild symptomatic infections are still reported. It is not excluded that genetic host factors may also play a role.

Since strain-specific immunity to malarial infection is supposed to occur when the exposed individual developed competent immune responses to the majority of circulating variant antigens (Bull \& Marsh 2002, Hviid \& Staalsoe 2004), it may be hypothesized that the genotypes identified in the non-symptomatic infection-associated parasites are associated to variant antigens better recognized than the antigens encoded by variant genes associated to symptomatic infection-associated parasite genotypes. Again, as long as a differential immune response is not measured, any hypothesis in this direction is highly speculative.

Variant genes encoding erythrocyte surface exposed antigens such as the PfEMP1 antigen, encoded by the var gene family ( $\mathrm{Su}$ et al. 1995) are mostly found in subtelomeric regions of all $P$. falciparum chromosomes (Gardner et al. 2002) and it is believed that these genes are rapidly redistributed during meiosis (Freitas-Junior et al. 2000). Accordingly, a fine-analysis of linkage disequilibrium of microsatellites along all $P$. falciparum chromosomes showed that the telomere ends are subject to far more recombination events than centromeric regions (Mu et al. 2005), where the herein used microsatellites are localized (Anderson et al. 1999). Therefore, it was not expected to see any association of the relatively selection-neutral (only the marker TA1 codes for antigen) markers with the observed form of infec- tion caused by the analysed parasite genotype. We hypothesize that this association may only be found in situations with few recombination events due to low transmission, but never in the case of intense transmission and consequently high rates of recombination as in many African areas (Mu et al. 2005). Actually, it is unknown to what rate microsatellite markers of a given genotype change during a mosquito passage and subsequent reinfection.

A future task will be to identify if symptomatic infection-associated genotypes carry other variant gene repertoires than non-symptomatic associated genotypes. In a recent study, the global repertoire of variant genes, namely var genes, was estimated significantly smaller in Western Amazon parasites than from other areas (Albrecht et al. 2006). This turns the massive sequencing of symptomatic- and asymptomatic infection associated repertoires a feasible and not an never-ending task, as would be expected from African settings (see a study by Bull and colleagues (Bull et al. 2005).

What are the general implications for malaria epidemiology in riverine regions with populations such as those living in the Candelária suburb? On one hand, contact with new circulating parasite strains may cause any time novel infections in otherwise semi-immune individuals, and as occurred with the herein identified non-symptomatic associated strains, individuals may slowly mount resistance also against these novel strains. On the other hand, circulating parasites even at very low levels, which do not cause symptoms in the local population, are sufficient to contaminate present mosquito vectors in the area (Alves et al. 2005). These then may eventually put at risk malaria-naïve persons entering the area, very probably resulting to epidemics similarly to those observed in the past in this area (Cruz 1910, Sawyer 1988).

\section{ACKNOWLEDGEMENTS}

To Drs Karin Kirchgatter and Marcelo U Ferreira for helpful discussions and critical reading of the manuscript. To the participants from the Candelária neighbourhood and Cepem for collaboration.

\section{REFERENCES}

Albrecht L, Merino EF, Hoffmann EH, Ferreira MU, de Mattos Ferreira RG, Osakabe AL, Dalla Martha RC, Ramharter M, Durham AM, Ferreira JE, Del Portillo HA, Wunderlich G 2006. Extense variant gene family repertoire overlap in Western Amazon Plasmodium falciparum isolates. Mol Biochem Parasitol 150: 157-165.

Alves FP, Durlacher RR, Menezes MJ, Krieger H, Silva LH, Camargo EP 2002. High prevalence of asymptomatic Plasmodium vivax and Plasmodium falciparum infections in native Amazonian populations. Am J Trop Med Hyg 66: 641-648.

Alves FP, Gil LH, Marrelli MT, Ribolla PE, Camargo EP, Da Silva LH 2005. Asymptomatic carriers of Plasmodium spp. as infection source for malaria vector mosquitoes in the Brazilian Amazon. J Med Entomol 42: 777-779.

Anderson TJ, Su XZ, Bockarie M, Lagog M, Day KP 1999. Twelve microsatellite markers for characterization of Plasmodium falciparum from finger-prick blood samples. Parasitology 119: 113-125. 
Ariey F, Hommel D, Le Scanf C, Duchemin JB, Peneau C, Hulin A, Sarthou JL, Reynes JM, Fandeur T, Mercereau-Puijalon O 2001. Association of severe malaria with a specific Plasmodium falciparum genotype in French Guiana. $J$ Infect Dis 184: 237-241.

Bull PC, Marsh K 2002. The role of antibodies to Plasmodium falciparum-infected-erythrocyte surface antigens in naturally acquired immunity to malaria. Trends Microbiol 10: 55-58.

Bull PC, Berriman M, Kyes S, Quail MA, Hall N, Kortok MM, Marsh K, Newbold CI 2005. Plasmodium falciparum Variant Surface Antigen Expression Patterns during Malaria. PLoS Pathog 1: e26.

Cruz O 1910. Considerações Gerais sobre as Condições Sanitárias do Rio Madeira, Papelaria Americana, Rio de Janeiro.

Druilhe P, Daubersies P, Patarapotikul J, Gentil C, Chene L, Chongsuphajaisiddhi T, Mellouk S, Langsley G 1998. A primary malarial infection is composed of a very wide range of genetically diverse but related parasites. J Clin Invest 101: 2008-2016.

Ferreira MU, Kimura ES, Camargo LM, Alexandre CO, da Silva LH, Katzin AM 1994. Antibody response against Plasmodium falciparum exoantigens and somatic antigens: a longitudinal survey in a rural community in Rondonia, western Brazilian Amazon. Acta Trop 57: 35-46.

Ferreira MU, Nair S, Hyunh TV, Kawamoto F, Anderson TJ 2002. Microsatellite characterization of Plasmodium falciparum from cerebral and uncomplicated malaria patients in southern Vietnam. J Clin Microbiol 40: 1854-1857.

Freitas-Junior LH, Bottius E, Pirrit LA, Deitsch KW, Scheidig C, Guinet F, Nehrbass U, Wellems TE, Scherf A 2000. Frequent ectopic recombination of virulence factor genes in telomeric chromosome clusters of P. falciparum. Nature 407: 1018-1022.

Gardner MJ, Hall N, Fung E, White O, Berriman M, Hyman RW, Carlton JM, Pain A, Nelson KE, Bowman S, Paulsen IT, James K, Eisen JA, Rutherford K, Salzberg SL, Craig A, Kyes S, Chan MS, Nene V, Shallom SJ, Suh B, Peterson J, Angiuoli S, Pertea M, Allen J, Selengut J, Haft D, Mather MW, Vaidya AB, Martin DM, Fairlamb AH, Fraunholz MJ, Roos DS, Ralph SA, McFadden GI, Cummings LM, Subramanian GM, Mungall C, Venter JC, Carucci DJ, Hoffman SL, Newbold C, Davis RW, Fraser CM, Barrell B 2002. Genome sequence of the human malaria parasite Plasmodium falciparum. Nature 419: 498-511.
Gil LH, Alves FP, Zieler H, Salcedo JM, Durlacher RR, Cunha RP, Tada MS, Camargo LM, Camargo EP, Pereira-da-Silva LH 2003. Seasonal malaria transmission and variation of anopheline density in two distinct endemic areas in Brazilian Amazonia. J Med Entomol 40: 636-641.

Hoffmann EH, Malafronte RS, Moraes-Avila SL, Osakabe AL, Wunderlich G, Durham AM, Ribolla PE, del Portillo HA, Ferreira MU 2006. Origins of sequence diversity in the malaria vaccine candidate merozoite surface protein-2 (MSP2) in Amazonian isolates of Plasmodium falciparum. Gene 376: $224-230$.

Hviid L, Staalsoe T 2004. Malaria immunity in infants: a special case of a general phenomenon? Trends Parasitol 20: 66-72.

Jafari S, Le Bras J, Bouchaud O, Durand R 2004. Plasmodium falciparum clonal population dynamics during malaria treatment. J Infect Dis 189: 195-203.

Machado RL, Povoa MM, Calvosa VS, Ferreira MU, Rossit AR, dos Santos EJ, Conway DJ 2004. Genetic structure of Plasmodium falciparum populations in the Brazilian Amazon region. J Infect Dis 190: 1547-1555.

Mu J, Awadalla P, Duan J, McGee K, Joy D, McVean G, Su XZ 2005. Recombination hotspots and population structure in Plasmodium falciparum. PLoS Biology 3: e335.

Sawyer D 1988. Frontier Malaria in the Amazon Region of Brazil: Types of Malaria and some Implications for Control. PAHO/WHO/TDR, Geneva.

Schlichtherle M, Wahlgren M, Perlmann H, Scherf A2000. Methods in Malaria Research, Manassas, Virginia, MR4/ATCC.

Schneider S, Roessli D, Excoffier L 2000. Arlequin ver. 2.000: A software for population genetics data anlaysis. Genetics and Biometry laboratory, University of Geneva.

Snounou G 1996. Detection and identification of the four malaria parasite species infecting humans by PCR amplification. Methods Mol Biol 50: 263-291.

Snow RW, Guerra CA, Noor AM, Myint HY, Hay SI 2005. The global distribution of clinical episodes of Plasmodium falciparum malaria. Nature 434: 214-7.

$\mathrm{Su}$ XZ, Heatwole VM, Wertheimer SP, Guinet F, Herrfeldt JA, Peterson DS, Ravetch JA, Wellems TE 1995. The large diverse gene family var encodes proteins involved in cytoadherence and antigenic variation of Plasmodium falciparum-infected erythrocytes. Cell 82: 89-100. 